Case Report

\title{
Daily Vaginal Application of Dienogest (Visanne $\odot$ ) for 3 Months in Symptomatic Deeply Infiltrating Rectovaginal Endometriosis: A Possible New Treatment Approach?
}

\author{
Andreas D. Ebert \\ Praxis für Frauengesundheit, Gynäkologie und Geburtshilfe, Nürnberger Strasse 67, \\ 10787 Berlin, Germany \\ Correspondence should be addressed to Andreas D. Ebert; adebert@gmx.de
}

Received 13 February 2018; Accepted 3 April 2018; Published 10 May 2018

Academic Editor: Maria Grazia Porpora

Copyright (C) 2018 Andreas D. Ebert. This is an open access article distributed under the Creative Commons Attribution License, which permits unrestricted use, distribution, and reproduction in any medium, provided the original work is properly cited.

A 27-year-old patient suffering from deeply infiltrating rectovaginal endometriosis was treated with $2 \mathrm{mg} /$ day dienogest vaginally for 3 months. The therapy was tolerated very well. The patient reported less side effects compared to the oral use of dienogest. After 3 months of dienogest treatment, the rectovaginal gynecological examination identified the visible vaginal part of endometriosis in remission. The firm endometriosis node approximately $3 \mathrm{~cm}$ in size and approximately $10 \mathrm{~cm}$ ab ano was still palpable, but it was much less painful. The laboratory values for luteinizing hormone (LH) and follicle-stimulating hormone (FSH) were unremarkable, with an LH/FSH quotient of 0.7 during dienogest treatment, while 17- $\beta$ estradiol and progesterone were suppressed. At palpation and vaginal ultrasonography, there was no change in the findings before and after 3 months of dienogest treatment, but the patient was now de facto asymptomatic. To the best of our knowledge, this is the first report of a vaginal dienogest treatment in symptomatic deeply infiltrating rectovaginal endometriosis. Vaginal administration of dienogest should receive further investigation in pharmacokinetic and clinical studies.

\section{Introduction}

Symptomatic deeply infiltrating rectovaginal endometriosis with bowel involvement is a diagnostic and therapeutic challenge [1-5].

Oral administration of dienogest (Visanne@) is currently approved in Germany for the treatment of endometriosis alongside subcutaneous application of leuprorelin acetate (Enantone $\odot$, Trenantone $\odot$ ). Due to its lower costs and narrower range of side effects, dienogest is currently the drug treatment of choice in comparison with gonadotropinreleasing hormone (GnRH) analogues [6]. In terms of their effects and side effects, the two treatment approaches are equivalent [7-10]. Research studies to date have been carried out with oral administration of dienogest $2 \mathrm{mg} / \mathrm{d}$ [11-14]. To the best of our knowledge, there have as yet been no reports on trials of vaginal treatment with $2 \mathrm{mg} / \mathrm{d}$ dienogest in patients with symptomatic deeply infiltrating endometriosis.

\section{Case Presentation}

A 27-year-old woman (gravida I, para I; menarche at age 13) presented on 1 October 2017 due to secondary dysmenorrhea that she was suffering from since the age of 25 , dyspareunia with back pain, constipation with perimenstrual tympanites, and contact bleeding in a case of known rectovaginal endometriosis. Her menstrual cycle was regular (27/4). Her visual analogue score for dysmenorrhea $\left(\mathrm{VAS}_{\text {dysmenorrhea }}\right)$ was 8. A rectovaginal gynecological examination revealed fresh endometriosis in the posterior fornix, with slight bleeding (Figure 1(a)). The vaginal part of the cervix was unremarkable on colposcopy, cytology, and smear testing. At approximately $10 \mathrm{~cm} \mathrm{ab}$ ano, palpation identified a typical firm, painful node with a diameter of approximately $3 \mathrm{~cm}$, and poorly displaceable bowel mucosa, which was also clearly visible on vaginal ultrasonography (Figure 2(a)). The bilateral renal ultrasound findings were unremarkable. It was known from 


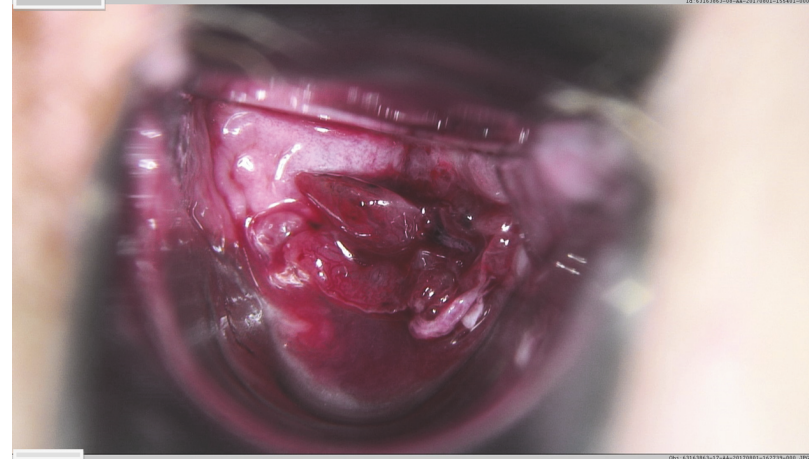

(a)

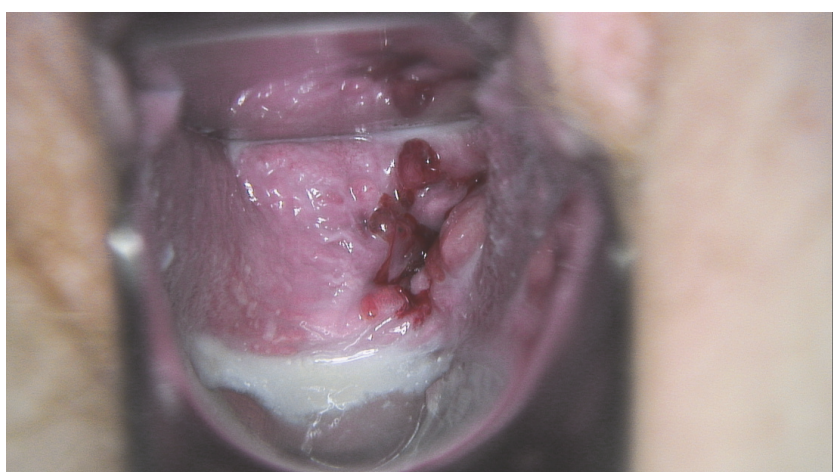

(b)

FiguRE 1: (a) Fresh, vulnerable, histologically confirmed rectovaginal endometriosis in the posterior fornix (Medivan video colposcope). The visual analogue score for the examination $\left(\mathrm{VAS}_{\text {examination }}\right.$ ) before dienogest therapy was 9. (b) Remission of the same endometriotic lesion in the posterior fornix 3 months later after daily vaginal dienogest application. $\mathrm{VAS}_{\text {examination }}$ score was now 4.

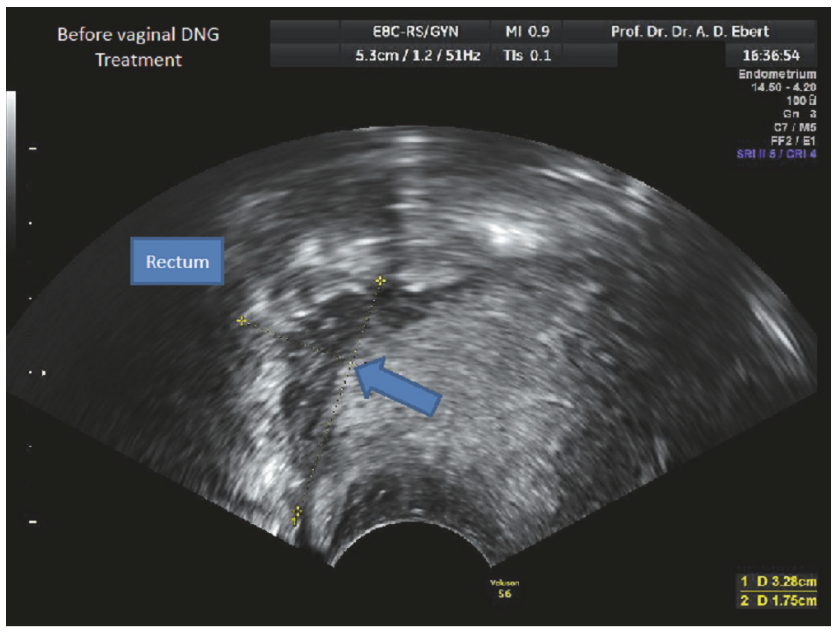

(a)

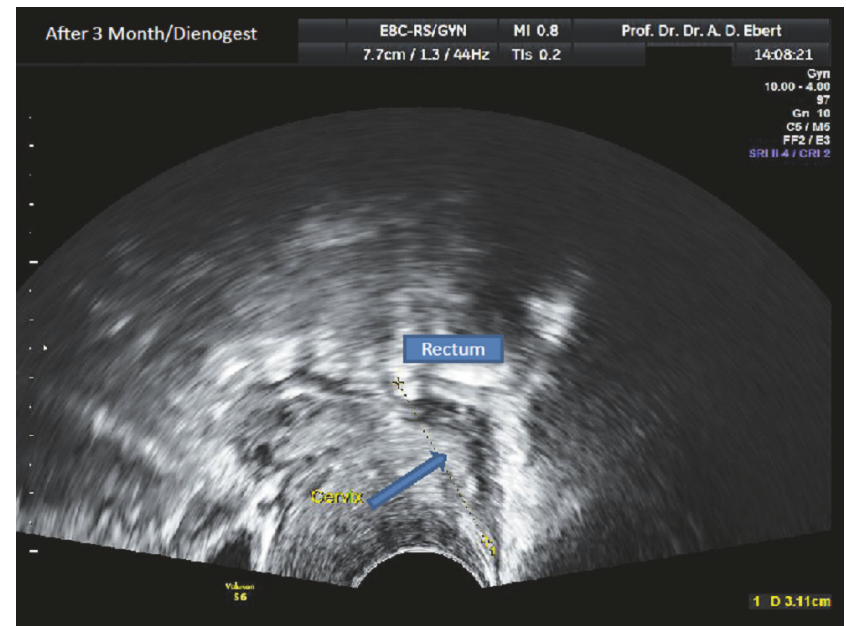

(b)

FIGURE 2: (a) Vaginal ultrasound appearance of the rectovaginal bowel involvement before the start of treatment in the symptomatic patient. (b) No change in the vaginal ultrasound findings after 3 months of vaginal dienogest administration ( $2 \mathrm{mg} / \mathrm{d})$ in the patient who was now de facto asymptomatic.

the patient's history that in February 2015 she had undergone a laparoscopy at a different hospital due to symptoms and wanting to have a baby; histology had confirmed deeply infiltrating endometriosis without atypia in the posterior fornix and pouch of Douglas. Adequate removal of the endometriosis was not carried out. The tubes were bilaterally patent. Postoperatively, the patient had taken dienogest ( $2 \mathrm{mg} / \mathrm{d}$ orally) up until August 2015, but she had very poor tolerance for it due to side effects (effluvium, blemished skin, sad mood). She became pregnant in October 2015 and delivered a boy at term in 2016 by emergency cesarean section due to premature placental detachment.

The endometriosis-related symptoms increased postpartum, with progressive deterioration in her quality of life. Despite this, the patient declined surgery due to fear of complications and for family and social reasons. She also declined endocrine treatment options (gonadotropinreleasing hormone antagonists or agonists, progestin-only pills, and oral contraceptives) due to the possible side effects. For this reason, the option of vaginal application of dienogest was discussed with the patient and implemented. The patient presented again after 3 months of vaginal dienogest treatment ( $2 \mathrm{mg} / \mathrm{d}$ vaginally). She reported minor vaginal spotting during the first 4 weeks of the treatment but had been amenorrhoeic for just under 8 weeks. She reported very good satisfaction with the treatment, after transient minimal side effects initially (slight skin blemishes, minimal discharge), and symptomatic freedom from the relevant endometriosisrelated symptoms. Slight contact bleeding occurred only during sex. No vaginal infections had occurred during the treatment period. The rectovaginal gynecological examination identified the endometriosis in remission in the posterior fornix (Figure 1(b)). The firm endometriosis node approximately $3 \mathrm{~cm}$ in size and approximately $10 \mathrm{~cm}$ ab ano was still palpable, but it was much less painful (Figure 2(a)). Bilateral renal ultrasonography was unremarkable. The laboratory 
values for luteinizing hormone (LH; $5.07 \mathrm{U} / \mathrm{L})$ and folliclestimulating hormone (FSH; 7.29 U/L) were unremarkable, with an LH/FSH quotient of 0.7 during dienogest treatment, while $17-\beta$ estradiol $(24.2 \mathrm{pg} / \mathrm{mL})$ and progesterone $(<0.05 \mathrm{ng} / \mathrm{mL})$ were suppressed. At palpation and vaginal ultrasonography, there was no change in the findings before and after 3 months of dienogest treatment, but the patient was now de facto asymptomatic. In addition, the vaginal part of endometriosis was clearly in remission as demonstrated by vaginal colposcopy (Figures 1(a) and 1(b)). At her express request, continuation of the vaginal dienogest treatment was agreed.

\section{Discussion}

In the present case, vaginal dienogest $(2 \mathrm{mg} / \mathrm{d})$ was administered for 3 months. During the treatment, remission occurred in the area of the vaginally visible part of the deeply infiltrating endometriosis (Figures 1(a) and 1(b)), while the rectal part showed no significant changes in size on palpation or ultrasonography (Figures 2(a) and 2(b)). Despite this, the patient became free of symptoms apart from contact bleeding-a major therapeutic success. The rectovaginal examination was also significantly less painful after 3 months of dienogest $\left(\operatorname{VAS}_{\text {examination }} 9\right.$ versus $\left.\operatorname{VAS}_{\text {examination }} 4\right)$. These findings are in accordance with our own experience and experience reported by others: before the size of the node declines, symptoms initially improve [14]. Despite the higher local dosage of dienogest, a reduction in the size of rectovaginal endometriosis nodes can probably only be observed clinically later on, since rectovaginal endometriosis always represents as adenomyofibromatous lesion [15], treatment-related remission of which takes time [16]. Dienogest was effectively resorbed vaginally, leading to therapeutic amenorrhea and the corresponding hormone findings in the present patient.

In principle, vaginal application of dienogest may be able to circumvent the hepatic first-pass effect and achieve higher concentrations of the active agent at the site of effect (e.g., a rectovaginal endometriosis node) with lower side effects than with oral administration [17]. The present patient thus reported that she found the vaginal application of dienogest much more tolerable than oral intake. A reduction in the dosage would also be conceivable with local dienogest administration. Studies with danazol, anastrozole, and contraceptive rings have shown that there is a reduction in lower abdominal pain and particularly in dysmenorrhea. However, a reduction in the size of rectovaginal nodes measured using ultrasound has not been reported by all investigators [17].

With vaginal application of dienogest (or other steroids), higher hormone concentrations can be achieved at the rectovaginal endometriosis node than with oral, intramuscular, or transcutaneous administration [17]. A prerequisite for this is correct placement of the active agents in the upper third of the vagina. For patients with symptomatic rectovaginal endometriosis who decline surgery or other treatment options for various reasons, vaginal dienogest application may thus represent a new approach to treatment, with low side effects. As vaginal application is familiar with other drugs [17], vaginal administration of dienogest (as well as other hormones) should receive further investigation in pharmacokinetic and clinical studies.

\section{Conflicts of Interest}

The author declares that there are no conflicts of interest regarding the publication of this article.

\section{References}

[1] G. Halis, S. Mechsner, and A. D. Ebert, "The diagnosis and treatment of deep infiltrating endometriosis," Deutsches Ärzteblatt International, vol. 107, pp. 446-455, 2010.

[2] N. Berlanda, E. Somigliana, M. P. Frattaruolo, L. Buggio, D. Dridi, and P. Vercellini, "Surgery versus hormonal therapy for deep endometriosis: is it a choice of the physician?" European Journal of Obstetrics \& Gynecology and Reproductive Biology, vol. 209, pp. 67-71, 2017.

[3] O. Donnez and H. Roman, "Choosing the right surgical technique for deep endometriosis: shaving, disc excision, or bowel resection?" Fertility and Sterility, vol. 108, no. 6, pp. 931-942, 2017.

[4] P. Vercellini, L. Buggio, and E. Somigliana, "Role of medical therapy in the management of deep rectovaginal endometriosis," Fertility and Sterility, vol. 108, no. 6, pp. 913-930, 2017.

[5] A. Vanhie, C. Meuleman, C. Tomassetti et al., "Consensus on Recording Deep Endometriosis Surgery: The CORDES statement," Human Reproduction, vol. 31, no. 6, pp. 1219-1223, 2016.

[6] U. Ulrich, O. Buchweitz, R. Greb et al., "National German Guideline (S2k): Guideline for the diagnosis and treatment of endometriosis," Geburtshilfe und Frauenheilkunde, vol. 74, no. 12, pp. 1104-1118, 2014.

[7] T. Strowitzki, J. Marr, C. Gerlinger, T. Faustmann, and C. Seitz, "Dienogest is as effective as leuprolide acetate in treating the painful symptoms of endometriosis: a 24 -week, randomized, multicentre, open-label trial," Human Reproduction, vol. 25, no. 3, pp. 633-641, 2010.

[8] T. Harada, M. Momoeda, Y. Taketani et al., "Dienogest is as effective as intranasal buserelin acetate for the relief of pain symptoms associated with endometriosis-a randomized, double-blind, multicenter, controlled trial," Fertility and Sterility, vol. 91, no. 3, pp. 675-681, 2009.

[9] D.-Y. Lee, J.-Y. Lee, J.-W. Seo, B.-K. Yoon, and D. Choi, "Gonadotropin-releasing hormone agonist with add-back treatment is as effective and tolerable as dienogest in preventing pain recurrence after laparoscopic surgery for endometriosis," Archives of Gynecology and Obstetrics, vol. 294, no. 6, pp. 12571263, 2016.

[10] M. A. Bedaiwy, C. Allaire, and S. Alfaraj, "Long-term medical management of endometriosis with dienogest and with a gonadotropin-releasing hormone agonist and add-back hormone therapy," Fertility and Sterility, vol. 107, no. 3, pp. 537-548, 2017.

[11] M. D. P. Andres, L. A. Lopes, E. C. Baracat, and S. Podgaec, "Dienogest in the treatment of endometriosis: systematic review," Archives of Gynecology and Obstetrics, vol. 292, no. 3, pp. 523-529, 2015.

[12] M. Momoeda, T. Harada, N. Terakawa et al., "Long-term use of dienogest for the treatment of endometriosis," Journal of 
Obstetrics and Gynaecology Research, vol. 35, no. 6, pp. 10691076, 2009.

[13] A. Maiorana, D. Incandela, F. Parazzini et al., "Efficacy of dienogest in improving pain in women with endometriosis: a 12-month single-center experience," Archives of Gynecology and Obstetrics, vol. 296, no. 3, pp. 429-433, 2017.

[14] J. P. Leonardo-Pinto, C. L. Benetti-Pinto, K. Cursino, and D. A. Yela, "Dienogest and deep infiltrating endometriosis: The remission of symptoms is not related to endometriosis nodule remission," European Journal of Obstetrics \& Gynecology and Reproductive Biology, vol. 211, pp. 108-111, 2017.

[15] R. Meyer, "Die Pathologie der Bindegewebsgeschwülste und Mischgeschwülste," in Handbuch der Gynäkologie. 3. Auflage, Band 6, J. F. Bergmann, München, W. Stoeckel, Ed., pp. 356-615, 1930.

[16] M. Harada, Y. Osuga, G. Izumi et al., "Dienogest, a new conservative strategy for extragenital endometriosis: A pilot study," Gynecological Endocrinology, vol. 27, no. 9, pp. 717-720, 2011.

[17] L. Buggio, C. Lazzari, E. Monti, G. Barbara, N. Berlanda, and P. Vercellini, “"Per vaginam” topical use of hormonal drugs in women with symptomatic deep endometriosis: a narrative literature review," Archives of Gynecology and Obstetrics, vol. 296, no. 3, pp. 435-444, 2017. 


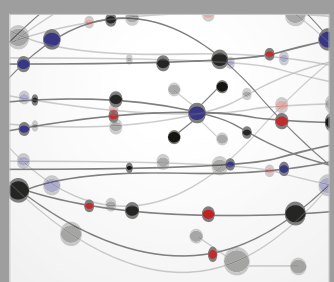

The Scientific World Journal
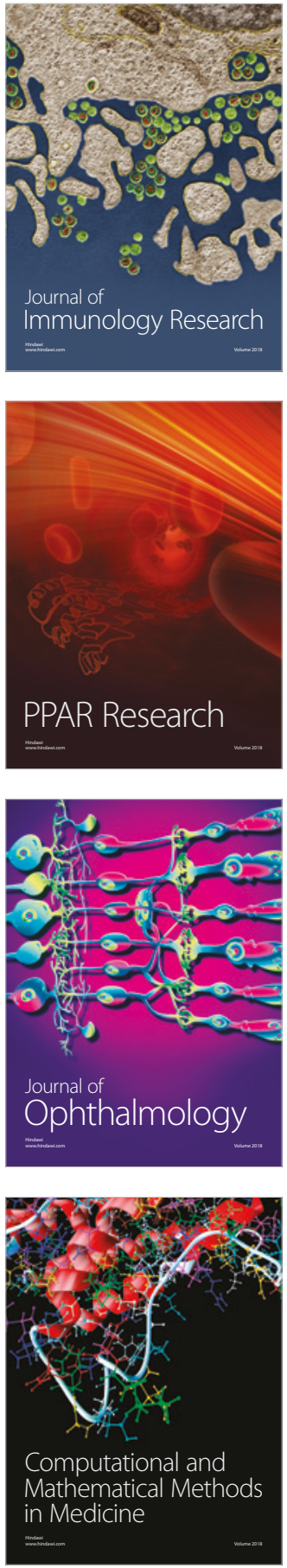

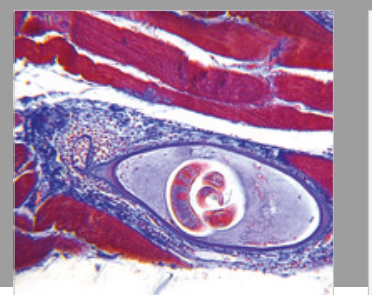

Gastroenterology Research and Practice

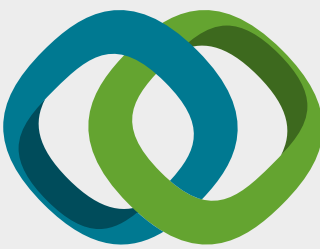

\section{Hindawi}

Submit your manuscripts at

www.hindawi.com
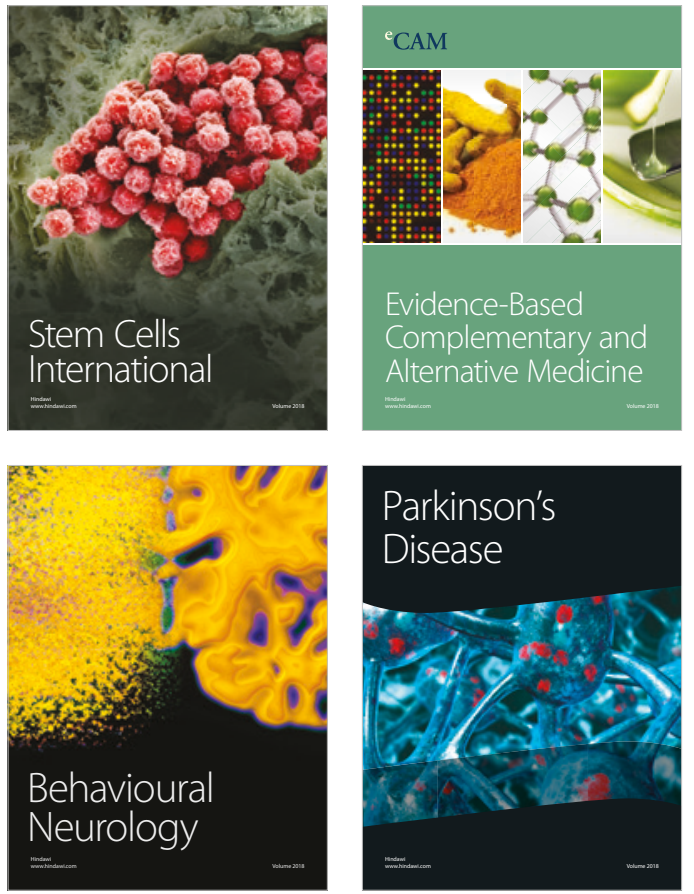

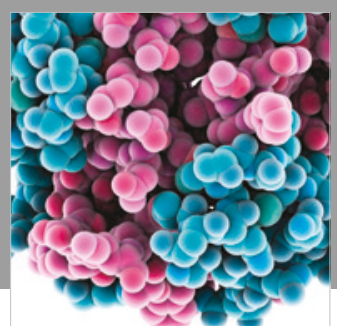

ournal of

Diabetes Research

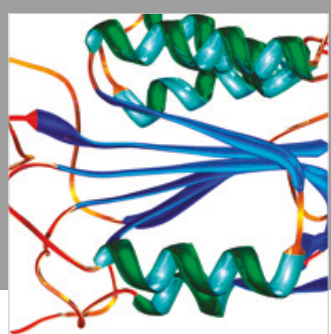

Disease Markers
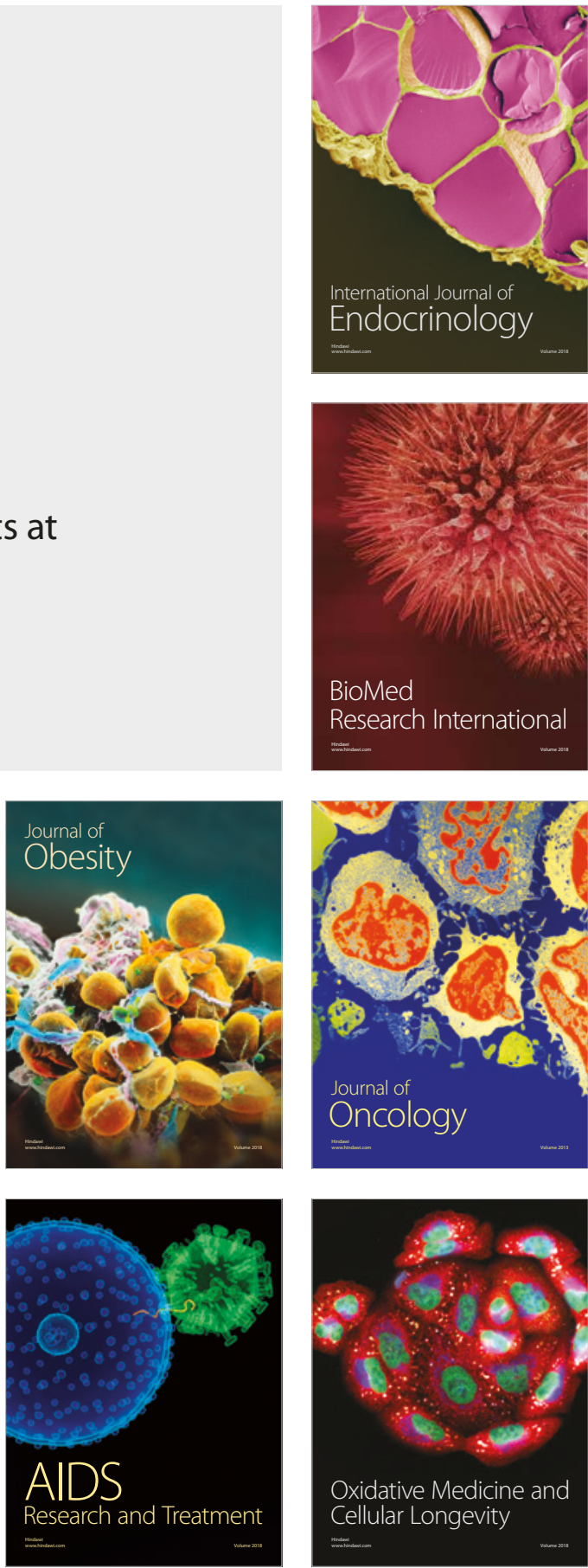